\title{
Generation of a Novel Transgenic Mouse Model for Bioluminescent Monitoring of Survivin Gene Activity in Vivo at Various Pathophysiological Processes
}

\section{Survivin Expression Overlaps with Stem Cell Markers}

Fengzhi Li, ${ }^{*}$ Qiuying Cheng, ${ }^{*}$ Xiang Ling, ${ }^{*}$ Aimee Stablewski, ${ }^{\dagger}$ Lei Tang, ${ }^{*}$ Barbara A. Foster, ${ }^{*}$ Candace S. Johnson, ${ }^{*}$ Youcef M. Rustum, ${ }^{\ddagger}$ and Carl W. Porter ${ }^{*}$

From the Departments of Pharmacology and Therapeutics," the Gene Targeting and Transgenic Facility, ${ }^{\dagger}$ and the Department of Cancer Biology, ${ }^{\ddagger}$ Roswell Park Cancer Institute, Buffalo, New York.

Survival has been implicated to play an important role in various pathophysiological processes. However, because of a lack of appropriate animal models, the role and dynamic expression of survivin during pathophysiology are not well defined. We generated a human survivin gene promoter-driven luciferase transgenic mouse model (SPlucTg) so that dynamic survivin gene activity can be monitored during various pathophysiological conditions using in vivo imaging. Our results show that, consistent with survivin positivity in testis, luciferase activity in normal SPlucTg mice was detected in the testis of male mice. Furthermore, similar to the known requirement of transient expression of survivin for pathophysiological responses, we observed a transient luciferase expression in castrated SPlucTg male mice after supplement of androgen. Significantly, it was reported that survivin expression turns on during mouse liver injury and regeneration; a transient and dose-dependent luciferase expression in the mouse liver was observed after administration of carbon tetrachloride into SPlucTg mice. We further demonstrated that luciferase activity closely correlates with endogenous survivin expression. We also demonstrated that only a subset of cells expresses survivin, and its expression overlaps with the expression of several stem cell markers tested. Thus, we have generated a unique animal model for analysis of diverse pathophysiological processes and possible stem cell distribution/ activity in vivo. (Am J Pathol 2010, 176:1629-1638; DOI: 10.2353/ajpath.2010.090414)

Evidence indicates that survivin, an inhibitor of apoptosis (IAP) family protein and a promoter of cell cycle and mitosis, ${ }^{1-3}$ plays an important role in cancer initiation ${ }^{4}$ and angiogenesis, ${ }^{5-7}$ tumor progression, drug/radiation resistance, ${ }^{8}$ and tumor relapse. ${ }^{3,9}$ Survivin may also play a role in other pathophysiological processes. ${ }^{10-12}$ These include embryonic development, hematopoietic cell survival and proliferation, T-cell development, multiple sclerosis, brain pathology, and pathophysiology of other organs including liver, pancreas, gastrointestine, testes, endometrium, and placenta. ${ }^{11}$ However, studies indicated that the behavior of survivin expression, subcellular localization, and/or gene regulation appear to be different during normal tissue turnover or repair versus cancer initiation and progression. ${ }^{11}$ Furthermore, in some cases, normal cell division, survival, and development happen in the absence of survivin ${ }^{13}$ or with differential requirement of survivin. ${ }^{14}$ Additionally, because of increased expression of survivin in cancer, the interaction of survivin molecules with other proteins may differ from normal cells and/or may exclusively occur in cancer

Supported in part by NIH R01 grants (CA109481, CA133241), a research grant (BCTR63806) from Susan G. Komen Breast Cancer Foundation and a research award/grant from Charlotte Geyer Foundation (to F.L.), and by shared resources supported by $\mathrm{NCl}$ Cancer Center Support Grant to Roswell Park Cancer Institute (CA016056). L.T. is a Ph.D. student of the Second West China Hospital, Sichuan University, supported by Chinese Government's Ph.D. training fellowship.

Accepted for publication December 14, 2009.

Supplemental material for this article can be found on http://ajp. amjpathol.org

Address reprint requests to Fengzhi Li, Ph.D., Department of Pharmacology and Therapeutics, Roswell Park Cancer Institute, Elm and Carlton Streets, CGP- L4301, Buffalo, NY 14263. E-mail: fengzhi.li@ roswellpark.org. 
cells. ${ }^{15,16}$ This partially explains the observations indicating that whereas abrogation of survivin expression or functions triggers significant apoptosis of cancer cells, it has minimal effects on normal cells and tissues. ${ }^{17-24}$ Thus, survivin appears to be an ideal cancer preventive and therapeutic target.

Targeting survivin for cancer treatment might cause little toxicity to normal tissues. Indeed, many natural chemopreventive and chemotherapeutic dietary components, such as resveratrol, silibinin, and sulindac ${ }^{25}$ as well as selenium, ${ }^{26}$ retinoid, ${ }^{27,28}$ and vitamin D (eg, calcitriol) $)^{29}$ down-regulate survivin expression in cancer cells. This is consistent with a role for survivin in oncogenesis. However, because of the lack of an appropriate in vivo animal model system, the role for survivin either in cancer-related or in other in vivo pathological processes ${ }^{11}$ remains to be elucidated.

Here, we report the generation of a novel transgenic mouse model that expresses the luciferase reporter gene as the human survivin gene surrogate under the control of a human survivin gene promoter. We demonstrated that this new mouse model possesses an active and highly responsive luciferase reporter system, which reflects the dynamic expression of endogenous survivin during pathology. We further show that survivin expression overlaps with several stem cell markers, which suggests that survivin may be a good stem cell marker as well. Our model has several unique features for in vivo imaging in comparison with the model previously reported. ${ }^{30}$ In our model, we used the human survivin promoter with sufficient length $(4.5 \mathrm{~kb})$, instead of using a mouse survivin proximal promoter ( $0.8 \mathrm{~kb}$; as a note, the design in Xia et al's report ${ }^{30}$ is good for studying the relationship between survivin expression and cell cycle/mitosis). Importantly, using the luciferase reporter as a surrogate to monitor survivin gene activity during various pathophysiological processes will increase sensitivity by several orders of magnitude in comparison with using GFP as a reporter for in vivo imaging, although GFP can provide strong signals. Therefore, with our model, it is now possible to monitor endogenous survivin gene activity through in vivo imaging of its surrogate luciferase activity during various pathophysiological processes. This mouse model has the potential to delineate the dynamic expression and role of survivin in cancer and other pathophysiological processes.

\section{Materials and Methods}

\section{Generation of Human Survivin Promoter-Driven Luciferase-Transgenic (SPLucTg) Mice}

A 4.5-kb human survivin promoter sequence starting from -1 at the $3^{\prime}$-end (the A in ATG codon of the survivin gene is designated as +1 ) that reflects the expression behavior of the endogenous survivin gene (cell cycle-dependent and -independent transcription control) ${ }^{31-33}$ was isolated and inserted upstream of the firefly luciferase reporter gene at the Sall and Hindlll sites of the pLuc vector, which is a home-made vector using pGEM3 as
A
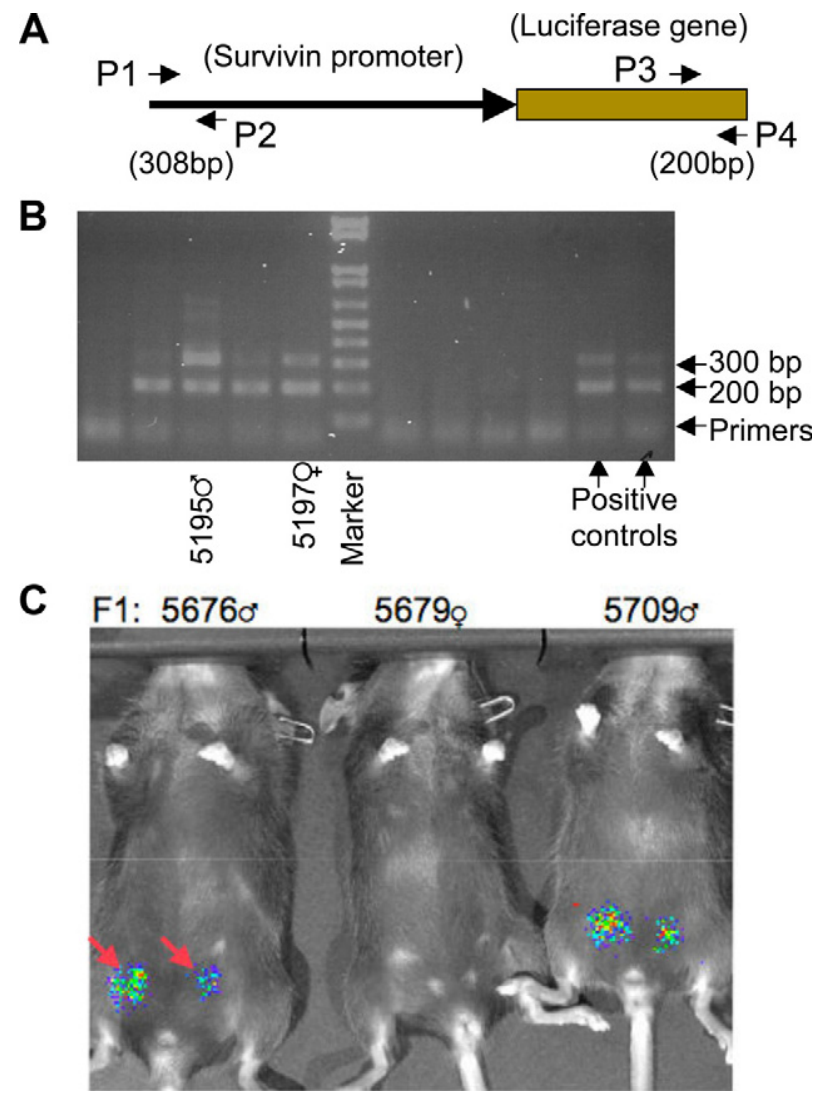

Figure 1. Generation of the human survivin promoter-driven luciferase reporter-transgenic (SPlucTg) mice. A: Diagram of the structure of the transgene cassette. Four primers used in PCR to determine genotype of the transgenic mouse are shown. B: Representative genotyping results for the transgenic mice. C: The luciferase expression profile in genotype-positive SPlucTg mice was determined by in vivo imaging. Red arrows indicate testes that show luciferase activity. $\delta$ indicates male mice; + , female mice.

the backbone. The resulting vector was first tested in both cancer (HeLa, MCF-7, PC-3, A549, and E0771) and HEK293 cells for testing activity. The verified vector was then digested with Sall and Sacl and the transgene cassette was purified using cesium chloride; the bacterial plasmid backbone was discarded. The purified transgene cassette DNA was microinjected into the pronuclei of day -0.5 embryos extracted from C57BL/6 mice (Jackson Laboratory, Bar Harbor, ME). Injected embryos were implanted into pseudo-pregnant female Swiss Webster mice (Taconi, Hudson, NY). Tail biopsies and subsequent DNA isolation was performed when the resulting pups were three to four weeks of age for genotype analysis. Presence of the transgene cassette was identified by PCR amplification of both the human survivin gene promoter and the luciferase gene sequence as shown in Figure 1A. Two human survivin promoter-specific primers at the $5^{\prime}$-region of the promoter (that do not recognize the endogenous mouse survivin sequence), P1 (5'-GCAGGAGAATCGCTTGAACCCGTGG-3') and P2 (5'-CCACTCACTTCTCTGGTTCTATGGCC-3'), were used to amplify a 308-bp PCR product. Two firefly luciferase gene-specific primers at the $3^{\prime}$-region of the gene, P3 (5'-GTGGATTACGTCGCCAGTCAAGTAAC-3') and P4 (5'CAATAGCTAAGAATTTCGTCATCGCTG-3'), were used 
to amplify a 200-bp PCR product. The PCR reaction and condition are as follows: $200 \mathrm{nmol} / \mathrm{L}$ for each primer, $1 \times P C R$ buffer with $1.2 \mathrm{mmol} / \mathrm{L} \mathrm{Mg}^{2+}, 200 \mu \mathrm{mol} / \mathrm{L}$ for each dNTP, 0.5\% DMSO, 0.5 to 1 unit TaqDNA polymerase (usb, Cleveland, $\mathrm{OH}$ ), and 1 to $2 \mu \mathrm{l}$ from total 150 tail DNA as templates in $25 \mu$ l total volume. PCR amplification was performed for 40 cycles at $94^{\circ} \mathrm{C} \times 4$ minutes for pre-denature and then 40 cycle of $94^{\circ} \mathrm{C} \times 30$ seconds, $54^{\circ} \mathrm{C} \times 30$ seconds and $72^{\circ} \mathrm{C} \times 1$ minute, followed by $94^{\circ} \mathrm{C} \times 10$ minutes and then held at $4^{\circ} \mathrm{C}$. Of note, plasmid DNA containing the survivin promoter-luciferase cassette was used as positive control. Of a further note, the procedure for generation of transgenic mice above was covered by the RPCI IACUC-approved mouse protocol 912M. Other mouse procedures (see below) were covered by $1070 \mathrm{M}$ and 1072M mouse protocols.

\section{Mouse Whole Body in Vivo Imaging}

Animal whole body imaging was performed to detect luciferase reporter activity using the Xenogen IVIS $₫$ in vivo Imaging System (Caliper Life Science, Hopkinton, MA). In each measurement, SPlucTg mice were intraperitoneally injected with D-luciferin potassium salt dissolved in PBS at a dose of $75 \mathrm{mg} / \mathrm{kg}$. Ten minutes after Dluciferin injection, mice were anesthetized with isoflurane at $5 \%$ mixed with air in a separate induction chamber for one minute and then transferred into the in vivo imaging chamber for detection of luciferase activity for two minutes at a maintenance condition of anesthesia at $2 \%$ to $2.5 \%$ of isoflurane.

\section{Mouse Castration and Tissue Re-Proliferation}

Twelve-week-old SPLucTg mice with a C57BL/6 background were castrated as described previously. ${ }^{34}$ After two weeks (14 days) the castrated mice were subcutaneously implanted with testosterone pellets. Luciferase activity was monitored using in vivo imaging on day 1,3 , $5,7,9,11,14$, and 17, post androgen replacement.

\section{Liver Injury and Regeneration}

For the liver injury with $\mathrm{CCl} 4$, we referenced the previous protocol. ${ }^{35}$ Briefly, at age of eight weeks, SPLucTg mice with a C57BL/6 background were intraperitoneally administrated with $10 \% \mathrm{CCl} 4$ solution in corn oil $(\mathrm{v} / \mathrm{v})$ at a dose from $50 \mu \mathrm{l}$ to $300 \mu \mathrm{l}$ per $25 \mathrm{~g}$ mice on Day 0 . Luciferase activity was monitored through in vivo imaging on day $1,2,3,4$, and 6 .

\section{In Vitro Luciferase Activity Assay and Western Blot Analysis}

SPLucTg mice at eight to ten weeks of age were intraperitoneally injected with a $10 \%$ of $\mathrm{CCl} 4$ solution in corn oils at a dose of $200 \mu \mathrm{l} / 25 \mathrm{~g}$ on Day 0. Mouse livers were isolated on day 1, 2, 3, 4, and 5 and homogenized using a PowerGen 125 homogenizer in $1 \times$ passive lysis buffer
(Promega; $0.5 \mathrm{~g}$ liver tissues per $\mathrm{ml}$ buffer) for determining luciferase activity by luciferase assay or in Western blot lysis buffer ( $0.5 \mathrm{~g}$ tissues per $\mathrm{ml}$ ) for determining endogenous survivin expression by Western blot using survivin antibody (FL-142, Santa Cruz). The homogenized lysates were cleared by $18,000 \mathrm{~g}$ centrifugation in $1.5 \mathrm{ml}$ Eppendorf tube for 10 minutes at $4^{\circ} \mathrm{C}$, and the resultant clear supernatant was used for luciferase assay or Western blots. Experimental procedures for data shown in the supplemental Table S1 at $h$ ttp://ajp.amjpathol.org are the same as above with the exception that a $5 \%$ of $\mathrm{CCl} 4$ solution in corn oils at a dose of $450 \mu \mathrm{l} / 25 \mathrm{~g}$ was injected intraperitoneally on Day 0 . Mice were euthanized and their livers were isolated 65 hours after $\mathrm{CCl} 4$ injection. Detailed methods related to luciferase assays and Western blots were described in our previous publications. ${ }^{36,37}$

\section{Liver Tissue Collection and Immunohistochemistry Analysis}

Liver tissues treated and untreated with $\mathrm{CCl} 4$ (5\% in coin oil, $400 \mu \mathrm{l} / 25 \mathrm{~g}$ ) were isolated 65 hours after intraperitoneal injection. The isolated tissues were immediately preserved in three different formats: buffered formalin, zinc fixative (formalin free), and frozen in OCT frozen sectioning medium, followed by paraffin embedding. Preservation of liver tissues in three formats would provide great options for best immunohistochemistry $(\mathrm{IHC})$ results with selected antibodies. Each of the paraffin-embedded liver tissues was multiply sectioned at $5 \mu \mathrm{m}$ and processed for IHC with primary antibodies for survivin (\#2808, Cell Signaling), CD90 (\#550543, BD Pharmingen), ABCG2 (ab24114, Abcam), CD133 (ab19898, Abcam). IHC analyses were performed following protocols described in our previous publications. ${ }^{38-40}$

\section{Statistical Analysis}

The in vivo image data were analyzed using the Livinglmage ${ }^{\circledR} 2.50 .1$ software in the package of the in vivo image system (Xenogen/Caliper LifeSciences, Hopkinton, MA). A two-group $t$ test assuming equal variance was used for the data in the supplemental Figure S1 (at http://ajp. amjpathol.org). The significance ( $P$ value) was set at the nominal level of 0.05 .

\section{Results}

\section{Identification and Functional Validation of the SPlucTg Mice}

A total of 20 offspring were born from 344 fertilized eggs microinjected with the human survivin promoter-driven luciferase reporter gene cassette. Genotype determination of the 20 transgenic mice using PCR with primers P1/P2 and P3/P4 (Figure 1A) identified five founder mice. Examples of these results are presented in Figure 1B. The founder mice were then crossed with wild-type 


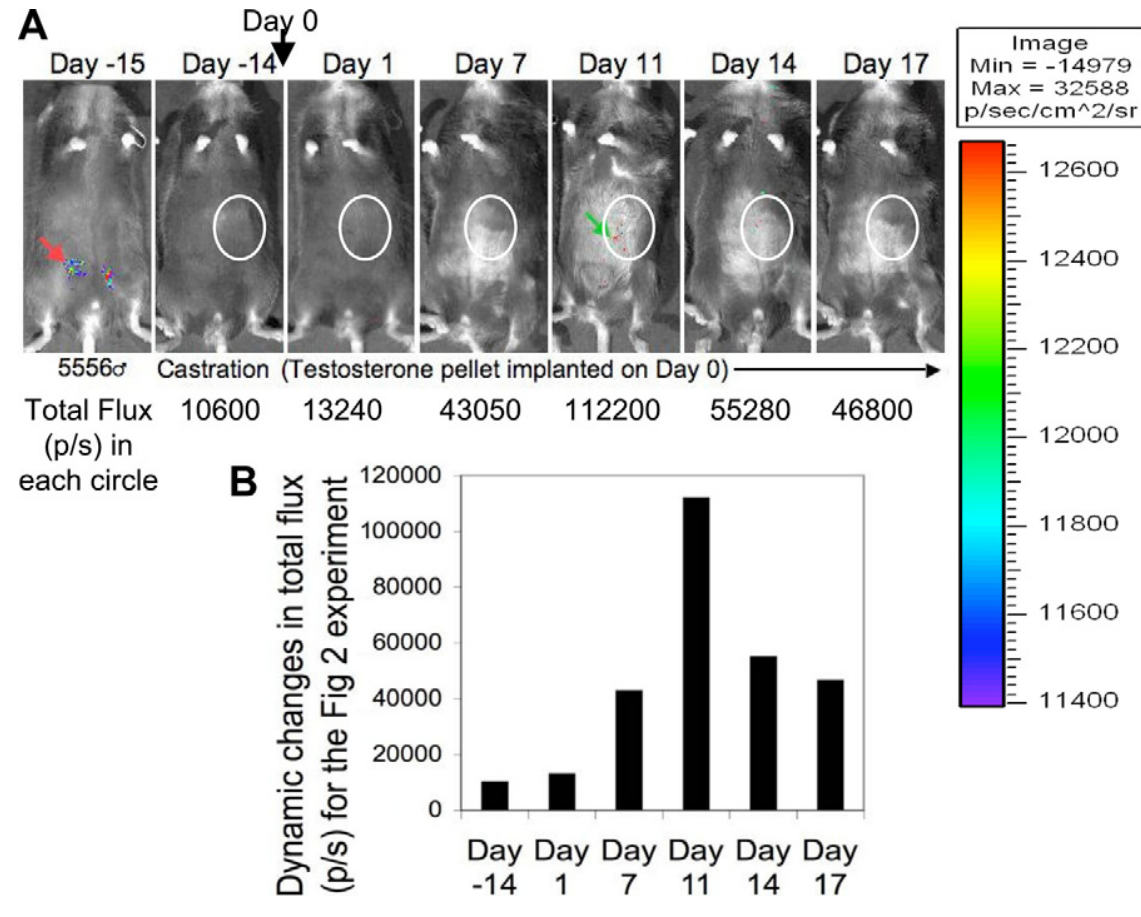

Figure 2. Human survivin promoter-driven luciferase activity (green arrow) during male SPlucTg mouse castration and regrowth with androgen replacement. A: Testosterone pellets were imbedded subcutaneously on day 0 (black arrow) onto SPlucTg mice, which were castrated 14 days ago. Luciferase activity was monitored by in vivo Imaging. The red arrow indicates testes showing luciferase activity before castration (day -15). B: The quantitative data derived from $\mathbf{A}$ are presented in a histogram format.
C57BL/6 mice to test germline transition of the transgene. Genotype determination using PCR indicated that four of the five founder lines successfully passed the transgene into offspring. Next, we determined whether the resultant F1 and F2 mice possessed a functional survivin promoter-luciferase reporter system. Our previous study identified testis as the only human organ that expresses high levels of survivin. We found that $\sim 60 \%$ to $70 \%$ of spermatogonia cells showing high survivin expression. ${ }^{38}$ Consistent with this observation, luciferase activity in SPlucTg mice was only detected in the testis (founder, F1 and F2) using an in vivo imaging system. Examples of three F1 SPlucTg mice are shown in Figure 1C (two males and one female).

\section{The Human Survivin Promoter Can Be Activated in Castrated SPlucTg Mice after Androgen Treatment}

Growing evidence indicates that normal cell proliferation is associated with a transient expression of survivin during various pathophysiologies. ${ }^{11}$ It is known that mouse prostate tissues will shrink after castration for two weeks. However, exogenous supplement of androgen could stimulate tissue proliferation and regeneration. Therefore, we tested whether we could detect luciferase activity in castrated SPLucTg mice after androgen treatment. Our experiments showed that supplement of testosterone pellets to the castrated SPLucTg mice gives rise to a transient luciferase activity (Figure 2, A and B). This experiment suggests that SPlucTg mice possess an active and regulated reporter system.
Transient and Dose-Dependent Activation of the Survivin Gene Surrogate during Injury and Repair/Regeneration of the Liver in SPlucTg Mice

Although the expression of survivin in normal adult liver is usually undetectable, a previous report demonstrated that survivin expression is turned on during mouse liver injury and regeneration after $\mathrm{CCl} 4$ administration. ${ }^{41}$ Therefore, we examined whether transient luciferase activity was apparent during CCl4-induced SPLucTg mouse liver injury and regeneration. Our experiment showed that CCl4-induced liver injury resulted in transient activation of the luciferase reporter system (Figure 3, A-H), further validating the physiological responsiveness of the survivin promoter-driven luciferase reporter gene cassette in SPLucTg mice. Importantly, luciferase activity intensity in response to $\mathrm{CCl} 4$ in the SPLucTg mouse liver is dosedependent (Figure 3).

\section{Luciferase Activity Reflects the Expression of Endogenous Survivin in SPlucTg Mice}

To determine the relationship between luciferase activity and endogenous survivin expression in the SPlucTg mice, we determined expression of both survivin and luciferase during $\mathrm{CCl} 4$-induced liver injury and regeneration in SPLucTg mice over a period of five days after $\mathrm{CCl} 4$ administration (Figure 4). Our results revealed that luciferase activity determined by in vitro luciferase activity assays, and endogenous survivin expression determined by Western blot analysis, mirror well. Similar to the expression pattern of endogenous survivin, in 
A $5815 \mathrm{~s}$, after $\mathrm{CCl}_{4}(10 \%, 50 \mathrm{\mu l} / 25 \mathrm{~g})$ i.p. injection
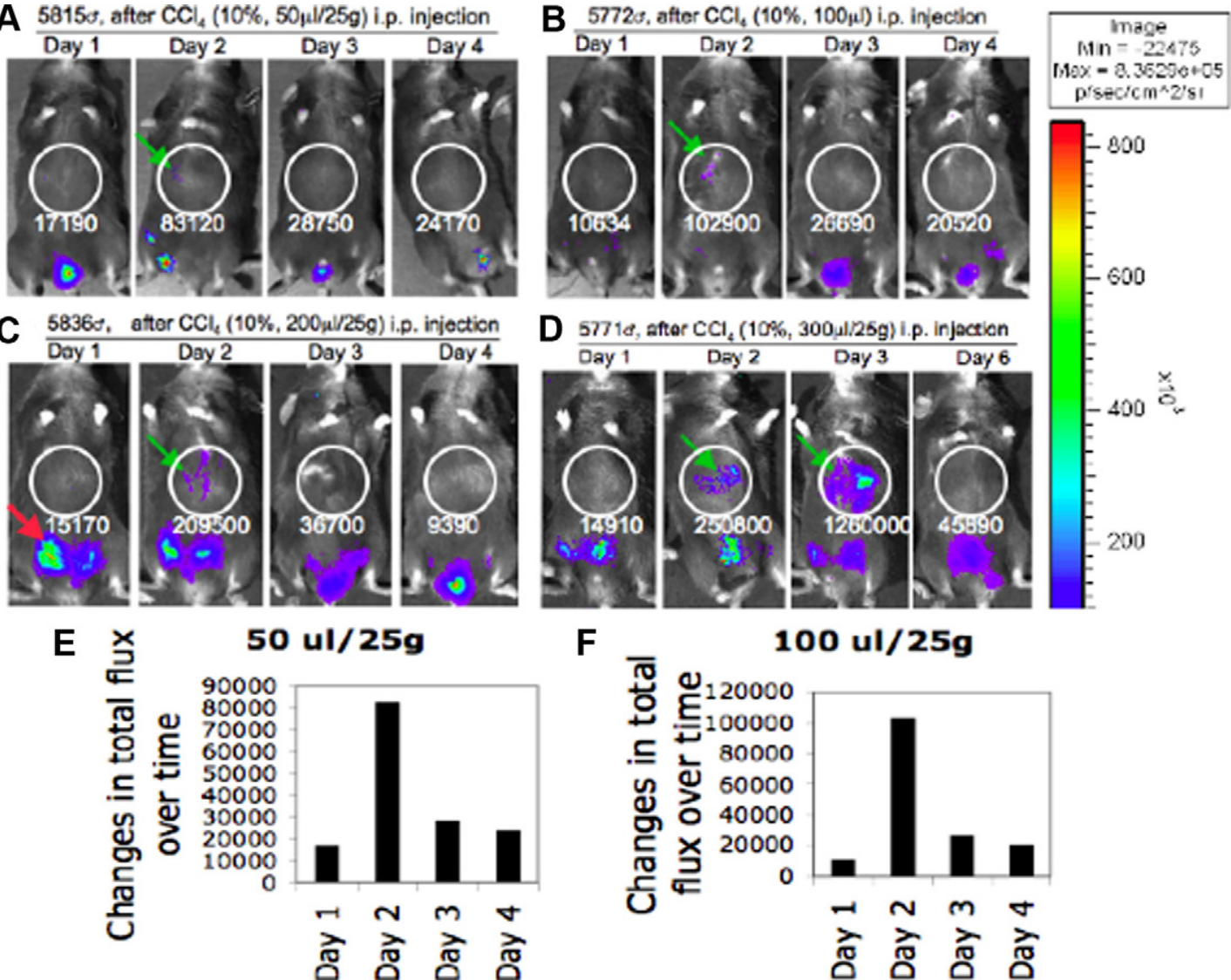

$\mathbf{F}$
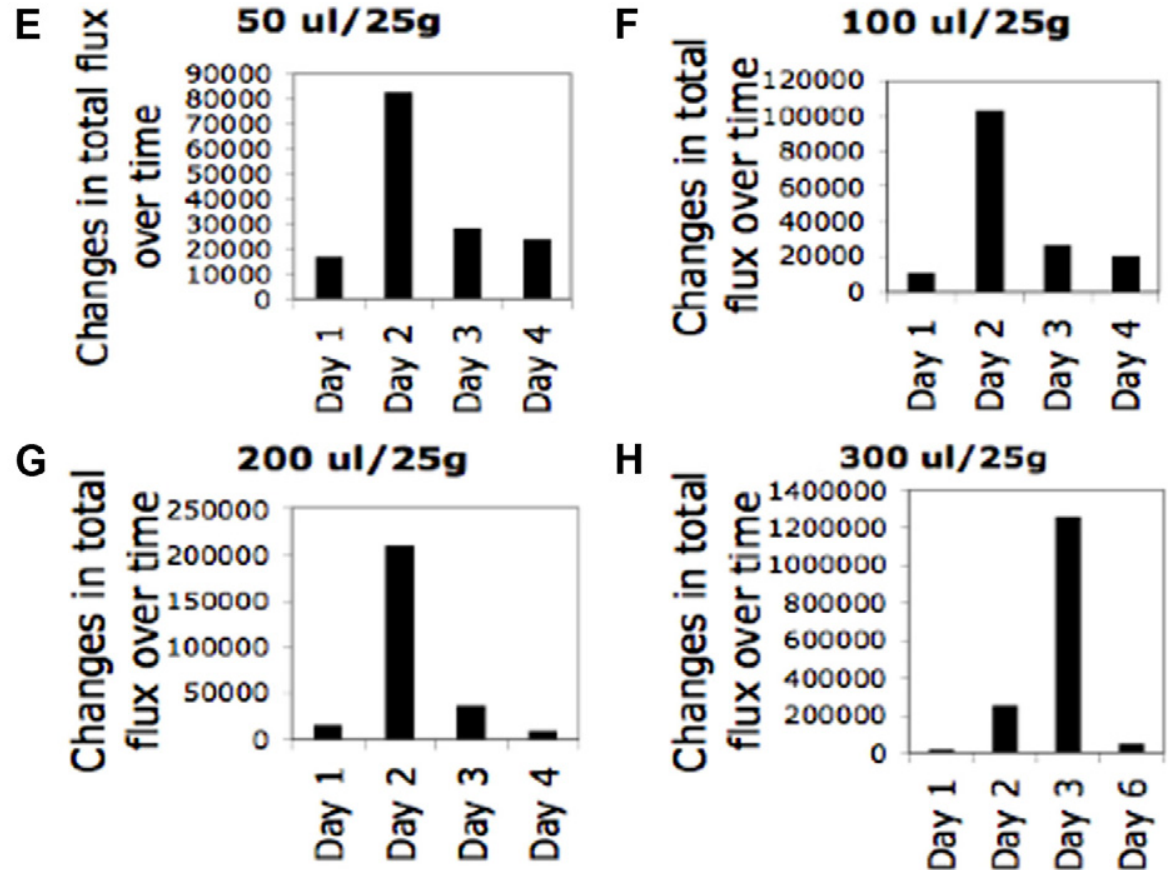

H

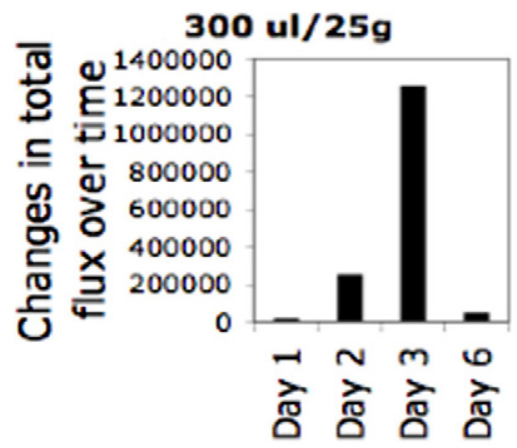

Figure 3. Human survivin promoter-driven luciferase activity (green arrow) during CCl4-induced SPlucTg mouse liver injury and repair processes. A-D: A 10\% (v/v) of CCl4 solution in corn oil was injected intraperitoneally on Day 0. Administered doses and the respective imaging day are indicated, respectively. The red arrow points the location of the testes, which are known to be positive for luciferase activity. E-H: The quantitative data derived from A-D are presented in histogram formats, respectively.

vivo imaging indicated that on Day 1 after administration of CCl4, $90 \%$ mice show no bioluminescence $(n=$ 10), whereas on Day 2, $80 \%$ of experimental mice show bioluminescence. Thereafter, the percentage of mice shows luciferase activity is in turn decreased from Day 3 to Day 5 (by Day 5 90\% of the mice show no luciferase activity). Thus, our data revealed that there is a viable and sensitive luciferase reporter system in SPlucTg mice, which closely mimics endogenous survivin gene activity.

One critical issue for application of the SPlucTg mouse model is the variation of luciferase activity among different individual mice. Here, we provide additional supplemental data derived from a larger cohort size to determine the mouse responsive rate (percentage) to treatment as well as possible variations of luciferase activity among individual mice resulted from the same treatment (see Supplemental Table S1 at http://ajp.amjpathol.org). The data in this table showed that 1) individual offspring produced from same homozygous SPlucTg mice show a minimal variation in luciferase activity on treatment; 2) luciferase activity variation in offspring from different homozygous SPlucTg mice in the same mouse line is also minimal; and 


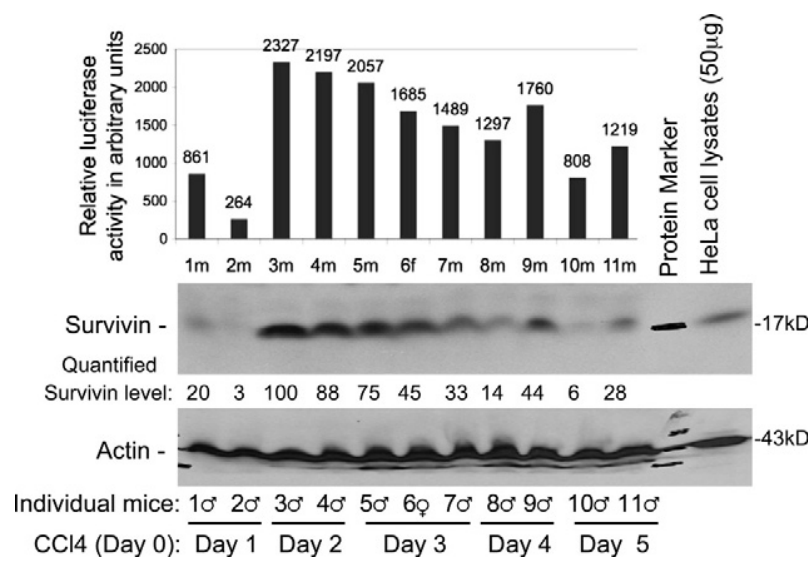

Figure 4. Association of luciferase activity with endogenous survivin expression in the CCl4-induced liver injury and repair in SPLucTg mouse model (Line 2). A $10 \%$ of $\mathrm{CCl} 4$ solution in corn oil at a dose of $200 \mu \mathrm{l} / 25 \mathrm{~g}$ was injected intraperitoneally on Day 0 . Mice were sacrificed and livers were isolated on days 1, 2, 3, 4, and 5, respectively. After the isolated livers were lysed, luciferase activity (upper panel, mean of triplicate assays from same sample) and survivin expression (lower panel) were determined using luciferase activity assays and Western blot analysis, respectively. Examples of mice from each day were shown. HeLa cell lysates was used as a survivin positive control, and the molecular size of the protein markers in the protein marker lane was indicated. $\mathrm{m}$ indicates male mice; $\mathrm{f}$, female mice.

3) different mouse lines can show different sensitivity of responsiveness on $\mathrm{CCl} 4$ treatment (see discussion).

\section{Survivin Expression Overlaps with the Expression of Several Stem Cell Markers}

Evidence indicates that survivin may play a role in stem cell (SC) function and may be a superior SC marker. For example, during colorectal ${ }^{9}$ and other types ${ }^{42,43}$ of carcinogenesis, survivin increases during the transition from adenoma with low dysplasia to high dysplasia/carcinoma, which involves abnormal $\beta$-catenin/TCF-4 signaling. ${ }^{44-46}$ To pursue the possibility that survivin expression overlaps with other SC markers and is a functional molecule during liver organ/tissue repair, we determined the expression of survivin, the liver-specific SC marker, CD90, and two other universal SC markers, CD133, ABCG2 in the CCl4-induced liver repair mouse model. As shown in Figure 5, A and B, the expression of survivin, CD133, and CD90 colocalized around the vessel (active repairing area) in the injured but not uninjured liver. Moreover, individual survivin-positive cells show overlapping with CD133-, CD90-, and ABCG2-positive cells at the outside of active repairing areas, although we did not find cluster-positive cells around vessels for ABCG2. In contrast, there were no cells showing positive for these markers in the control liver. Furthermore, our experiments showed that only a small subset of cancer cells in cancer tissues express survivin (Figure $5 \mathrm{C}$ ), which would be expected for a SC marker. Together, these data demonstrated that survivin could be a superior SC marker and may play a role in SC function.

\section{Discussion}

\section{Issues Related to Generation of a Valid Transgenic Mouse Model}

We have developed SPlucTg mice that express the luciferase reporter gene under the control of the human survivin promoter in a manner consistent with expression of endogenous survivin in various pathophysiological conditions. We used the transgene cassette DNA without the bacterial plasmid backbone DNA for generation of transgenic mice to preclude methylation effects, which are known to occur after random integration into the mouse genome. ${ }^{47,48}$ Such a methylation event could result in an epigenetic modification known as "methylation spread," and might subsequently lead to methylation of the transgene cassette, resulting in silencing of transgene expression. Another fundamental issue is whether the human survivin promoter used in the study represents the behavior of the endogenous survivin gene promoter. To this point, we isolated a 4.5-kb DNA fragment as a putative entire human survivin promoter, which is evidenced by several observations. Our initial studies on the human survivin gene promoter regulation indicated that whereas the promoter at $2840 \mathrm{bp}$ shows its promoter activity similar to its $1430 \mathrm{bp}$, its 6270-bp promoter neutralized its promoter activity by half, ${ }^{31}$ suggesting that there are additional inhibitory DNA motifs upstream of its 2840-bp promoter. Additionally, we found that there is similar promoter activity between its $6270-\mathrm{kb}$ promoter and its 4500-bp promoter (unpublished observation), suggesting that the 4.5-kb survivin promoter likely represents the entire human survivin promoter. Importantly, our previous study indicated that the 38-bp DNA fragment just upstream of the survivin translation start site (ATG) is critical for cell cycle-dependent expression of survivin. ${ }^{32}$ The $4.5-\mathrm{kb}$ survivin promoter used in this study includes this 38-bp DNA fragment as well. Therefore it contains all of the required DNA motifs for cell cycle-dependent regulation of survivin expression. ${ }^{32,33}$ Furthermore, this promoter was tested and verified in cancer cell-based ex vivo systems with a number of ligands including Hedamycin and Hoechst $33342^{36,49}$ before being used for generation of transgenic mice. We chose to use the human survivin promoter instead of the mouse survivin promoter to generate a transgenic mouse model because we have much more information available on human survivin promoter regulation than on mouse survivin promoter regulation. Secondly, we hope that the human survivin promoter-driven luciferase reporter may reflect a closer situation by use of this model to mimic human tumor initiation, progression, and metastasis. However, we understand and agree that both survivin promoters (human versus mouse) have advantages and disadvantages for application of such a mouse model in various pathophysiological processes.

Additionally, we generated several founder-mouse lines to identify the most sensitive line for applications. Of the five lines, one failed to pass the transgene onto the next generation, and of the four remaining lines, Line 2 was found to have the most sensitive responses to 

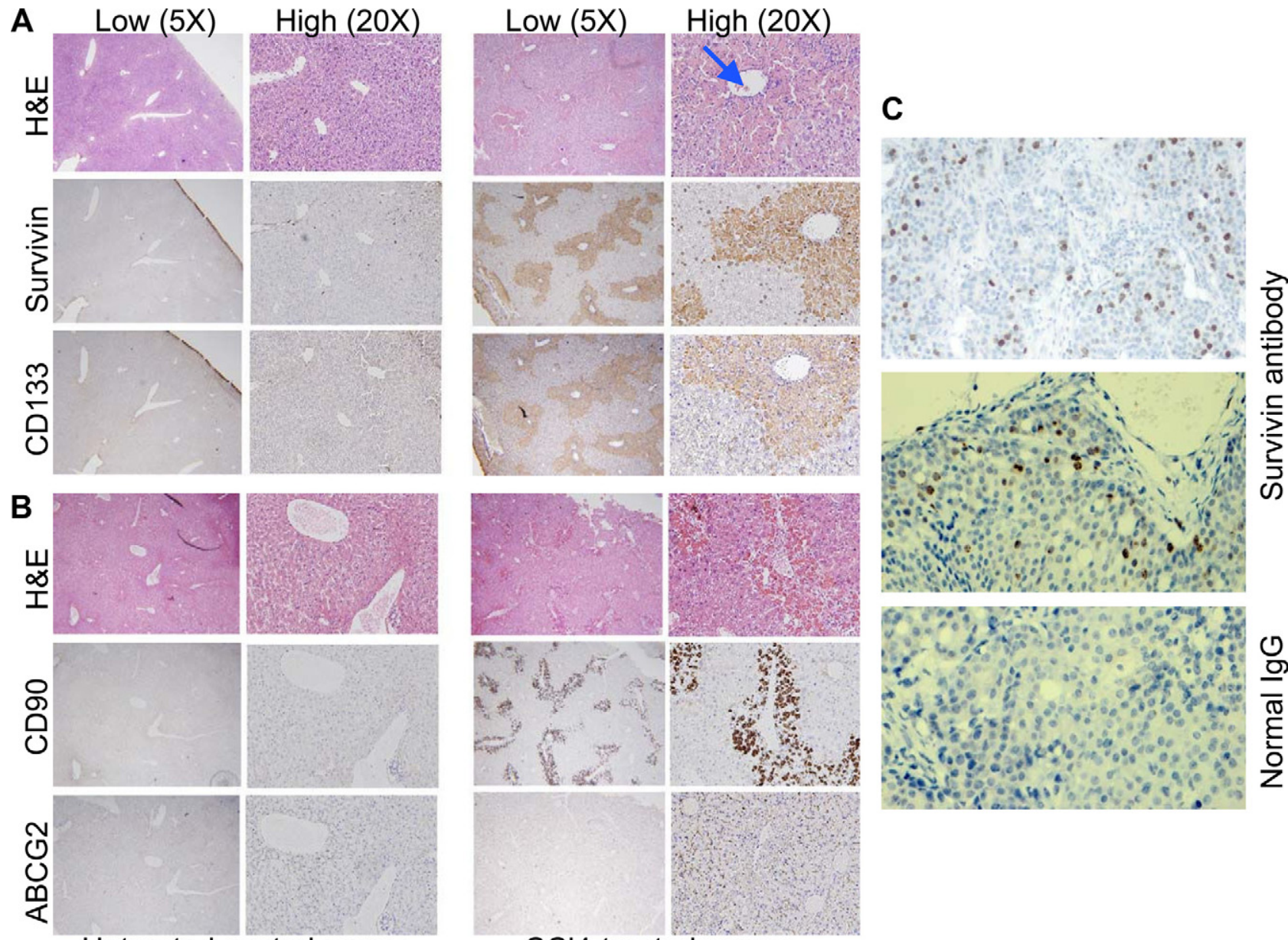

Untreated control mouse

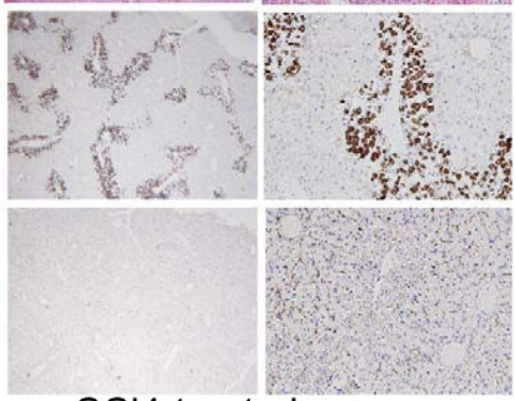

CCI4-treated mouse

Figure 5. The pattern of survivin expression during liver injury and repair overlaps with stem cell markers. A and $\mathbf{B}$ : The treated condition is $5 \% \mathrm{CCl} 4,400 \mu \mathrm{l} / 25 \mathrm{~g}$ Normal liver and CCl4-treated liver tissues were isolated 65 hours after treatment and analyzed by IHC as shown. An example vessel is indicated by the arrow. The liver tissues in A were fixed with buffered formalin, which works well for survivin and CD133 antibodies. The liver tissues in (B) were fixed with zinc fixative, which works well for CD90 and ABCG2 antibodies. An image from both low magnification and high magnification in each situation is shown. C: Only a small subset of cancer cells express survivin. Human breast cancer (upper panel) and mouse carcinoma (middle panel) stained with survivin rabbit mAb (\#2808, Cell Signaling). Mouse carcinoma stained with normal rabbit IgG.

treatment (refer to the supplemental Table S1 at $h t t p: / /$ ajp.amjpathol.org for more information) and is the best suitable line for mimicking endogenous survivin expression and regulation. The data in Supplemental Table S1 (at http://ajp.amjpathol.org) indicated that although different mouse lines show different sensitivity of responsiveness on $\mathrm{CCl} 4$ treatment, individual mice from the same parental SPlucTg mice or from different parental SPlucTg mice in the same line show minimal and well acceptable variation in luciferase activity on treatment. Based on this information, experiments using offspring derived from the same line homozygous SPlucTg mice to cross with other tumor mouse models for studying the role and expression of survivin during tumorigenesis should have no potential problems related to batch-to-batch and individual-to-individual variations. Importantly, the luciferase activity variations shown in individual mice in Supplemental Table S1 (see http://ajp.amjpathol.org) likely reflect the endogenous survivin response to treatment at the defined dose and time point used. This notion was well supported by the data provided in Figure 4 in the article. Thus, the mouse model would provide a powerful tool for many potential applications including those discussed in the article (see below).

\section{Potential Pitfalls for Application of this Transgenic Mouse Model}

Initial studies indicated that production of a high level of survivin mRNA is critical for maintenance of survivin protein expression during cell proliferation, ${ }^{32}$ that survivin expression is largely controlled by transcription, ${ }^{31,32}$ and that p53, as a major transcription factor, plays an important role in survivin transcription control in association with other transcription factors. ${ }^{50-53}$ Although increasing survivin protein expression may not always result from transcription, the presence of sufficient amounts of survivin mRNA is important. For example, although IGF-1/ mTOR signaling does not directly stimulate the production of more survivin mRNA, it was shown that IGF-1/ mTOR signaling needs survivin mRNA to increase translation. ${ }^{54}$ Moreover, whereas the ubiquitin-proteasome pathway plays a role in rapid survivin degradation 
in a cell cycle-dependent manner, ${ }^{55}$ studies using a mouse survivin promoter-driven GFP-transgenic mouse model indicated that survivin gene expression is largely mitosis-independent in vivo but regulated by $\mathrm{p53.}{ }^{30}$ Based on these findings, we believe that the transgenic mouse model generated in this study will be uniquely useful for monitoring survivin gene activity during various pathophysiological processes. However, in certain physiological cases, this model could be inaccurate or even incorrect regarding survivin gene activity. For example, it was reported that cell proliferation and maturation in the bone marrow is accompanied by survivin expression. ${ }^{56-59}$ We failed to detect the presence of luciferase activity in the bone marrow using in vivo and ex vivo imaging or in vitro luciferase assay. However, we are able to easily detect survivin mRNA and protein expression in the mouse bone marrow by real-time RT-PCR and western blots, which is consistent with our previous finding using immunohistochemistry. ${ }^{38}$ As an additional note, it appears that there is a trend that luminescence intensity increases in testes with increasing $\mathrm{CCl} 4$ dose as shown in Figure 3. This phenomenon suggests that $\mathrm{CCl} 4$ administration may injure testis and stimulate testis cells to express survivin as well. All of these interesting observations are currently under investigation in our laboratory.

Previously, our lab found that estrogen induces survivin expression in breast cancer cells, ${ }^{60}$ and both breast and ovarian cancer tissues express survivin. However, there is no survivin expression in human normal breast and ovary tissues. ${ }^{38}$ To delineate the mechanism for survivin negativity in human breast and ovary tissues, we used the p53 negative and ER $\alpha$ low Saos-2 cells to determine whether wild-type and mutant p53 can show different regulation of survivin expression with and without estrogen treatment. We found that wild-type p53 but not mutant p53 can effectively block ER $\alpha$-mediated upregulation of survivin promoter activity in the present or absence of estrogen (see the supplemental Fig. S1 at http://ajp.amjpathol.org). These data imply a possible mechanism for survivin negativity in human breast and ovary tissues through suppression by wild-type p53.

\section{Issues Related to Versatile Applications of the Generated Mouse Model as a Tool}

Although evidence indicates a role for survivin in the promotion of tumor invasion, metastasis, and tumor recurrence, ${ }^{61-65}$ the precise role for survivin in these processes has not been well defined in vivo. This is in part because the expression of survivin cannot be monitored in living animals without sacrificing mice during these processes. The SPlucTg mouse model generated in this study will help to fill this gap and can be used to monitor the expression of survivin during cancer initiation, tumor progression, and metastasis in living animals by in vivo imaging. For example, one could use a carcinogen such as DMBA to initiate tumor and then apply a tumor promoter such as PMA to further stimulate tumor development using the generated mouse model for the studies. Alternatively, one could cross the mouse model gener- ated in this study with other cancer-susceptible mouse models (such as the TRAMP mouse model or the p53/Rb double knockout mouse model) to create hybrid cancer mouse models to perform the studies. In short, the use of this animal model should facilitate elucidation of the expression and possible role for survivin during cancer initiation, tumor progression, and metastasis.

An additional issue relevant to the application of this animal model is that during liver injury and repair processes, our $\mathrm{IHC}$ experiments demonstrated that the expression of survivin aligns closely with the stem cell markers (CD133, CD90 [a liver-specific stem cell marker], and ABCG2), whereas ABCG2 does not overlap with CD133 and CD90 (Figure 5, A and B). The observation raises an important notion as to whether survivin might represent a superior stem cell marker and may play an important role in stem cell biology. Consistent with this possibility, our data (Figure 5C) in this report as well as our previous studies indicated that survivin is expressed in a very small subset of cell populations in normal proliferative tissues $^{38}$ and in cancer tissues, whereas other studies also suggest a possible involvement of survivin in stem cells. ${ }^{44,66,67}$ Furthermore, computer analysis of the death-from-cancer signature genes indicating that cancer cells with a stem cell-like expression profile possess three characteristics: increased IAP expression, activated mitotic spindle check point proteins, and elevated expression of cell cycle control proteins. ${ }^{68}$ Importantly, survivin is a key member of the IAP family and possesses all these characteristics-apoptosis inhibition, mitosis control, and cell cycle promotion. ${ }^{1-3}$ Together, survivin appears to be a stem cell marker, and tracking luciferase activity by in vivo imaging may be able to track stem cell activity. We propose that in terms of using survivin as a stem cell marker, our animal model may be useful in stem cell research especially in consideration of recent observations from our studies and others that tumor cell lines may not be the best model system to study cancer stem cells. ${ }^{69}$ That is, tumor-initiating cancer cell lines possess a large subset of cell population that can initiate tumors in vivo allo/xenografting models. ${ }^{69}$ Intriguingly, it was proposed that stem cells may not be a particular cell type but an emergent property of cell lineages under feedback control. ${ }^{70,71}$ Therefore, monitoring survivin gene activity may be a better strategy to trace cancer stem cells.

In sum, the model system generated in this study may have versatile applications in various pathophysiological processes including cancer and stem cell research.

\section{Acknowledgments}

We thank Bryan Gillard for his assistance with mouse castration and in vivo imaging, Dr. Wei-Dong Yu for assistance in the in vivo imaging analysis, Dr. Debora Kramer for critical reading of the manuscript, and Dr. Mike Moser for animal protocol support. We also thank Dawn Barnasr and Diane Poslinski for daily care of animals during the generation of transgenic mice. 


\section{References}

1. Altieri DC: Survivin in apoptosis control and cell cycle regulation in cancer. Prog Cell Cycle Res 2003, 5:447-452

2. Wheatley SP, McNeish IA: Survivin: a protein with dual roles in mitosis and apoptosis. Int Rev Cytol 2005, 247:35-88

3. Li F, Ling X: Survivin Study: an update of "What is the next wave?" J Cell Physiol 2006, 208:476-486

4. Dasgupta P, Kinkade R, Joshi B, Decook C, Haura E, Chellappan S: Nicotine inhibits apoptosis induced by chemotherapeutic drugs by up-regulating XIAP and survivin, Proc Natl Acad Sci USA 2006, 103:6332-6337

5. Iurlaro M, Demontis F, Corada M, Zanetta L, Drake C, Gariboldi M, Peiro S, Cano A, Navarro P, Cattelino A, Tognin S, Marchisio PC, Dejana E: VE-cadherin expression and clustering maintain low levels of survivin in endothelial cells. Am J Pathol 2004, 165:181-189

6. Conway EM, Zwerts F, Van Eygen V, DeVriese A, Nagai N, Luo W, Collen D: Survivin-dependent angiogenesis in ischemic brain: molecular mechanisms of hypoxia-induced up-regulation. Am J Pathol 2003, 163:935-946

7. Byun SJ, Choi KS, Park SH, Cho NW, Hyun Yoo C, Yun KJ, Koh YJ, Koh GY, So BJ, Yoon KH: Cartilage oligometric matrix protein-angiopoietin-1 promotes revascularization through increased survivin expression in dermal endothelial cells of skin grafts in mice. Am J Pathol 2007, 171:1682-1690

8. Virrey JJ, Guan S, Li W, Schonthal AH, Chen TC, Hofman FM: Increased survivin expression confers chemoresistance to tumor-associated endothelial cells. Am J Pathol 2008, 173:575-585

9. Li F: Role of survivin and its splice variants in tumorigenesis. $\mathrm{Br} J$ Cancer 2005, 92:212-216

10. Lechler P, Wu X, Bernhardt W, Campean V, Gastiger S, Hackenbeck T, Klanke B, Weidemann A, Warnecke C, Amann K, Engehausen D, Willam C, Eckardt KU, Rodel F, Wiesener MS: The tumor gene survivin is highly expressed in adult renal tubular cells: implications for a pathophysiological role in the kidney. Am J Pathol 2007, 171:1483-1498

11. Li F, Brattain MG: Role of the survivin gene in pathophysiology. Am J Pathol 2006, 169:1-11

12. Fukuda S, Pelus LM: Survivin, a cancer target with an emerging role in normal adult tissues. Mol Cancer Ther 2006, 5:1087-1098

13. Yang D, Welm A, Bishop JM: Cell division and cell survival in the absence of survivin. Proc Natl Acad Sci USA 2004, 101:15100-15105

14. Gurbuxani S, Xu Y, Keerthivasan G, Wickrema A, Crispino JD: Differential requirements for survivin in hematopoietic cell development. Proc Natl Acad Sci USA 2005, 102:11480-11485

15. O'Connor DS, Grossman D, Plescia J, Li F, Zhang H, Villa A, Tognin S, Marchisio PC, Altieri DC: Regulation of apoptosis at cell division by p34cdc2 phosphorylation of survivin. Proc Natl Acad Sci USA 2000 97:13103-13107

16. Fortugno P, Beltrami E, Plescia J, Fontana J, Pradhan D, Marchisio PC, Sessa WC, Altieri DC: Regulation of survivin function by Hsp90. Proc Natl Acad Sci USA 2003, 100:13791-13796

17. Mesri M, Wall NR, Li J, Kim RW, Altieri DC: Cancer gene therapy using a survivin mutant adenovirus. J Clin Invest 2001, 108:981-990

18. O'Connor DS, Wall NR, Porter AC, Altieri DC: A p34(cdc2) survival checkpoint in cancer. Cancer Cell 2002, 2:43-54

19. Wall NR, O'Connor DS, Plescia J, Pommier Y, Altieri DC: Suppression of survivin phosphorylation on Thr34 by flavopiridol enhances tumor cell apoptosis. Cancer Res 2003, 63:230-235

20. Plescia J, Salz W, Xia F, Pennati M, Zaffaroni N, Daidone MG, Meli M, Dohi T, Fortugno P, Nefedova Y, Gabrilovich DI, Colombo G, Altieri DC: Rational design of shepherdin, a novel anticancer agent. Cancer Cell 2005, 7:457-468

21. Xiang R, Mizutani N, Luo Y, Chiodoni C, Zhou H, Mizutani M, Ba Y, Becker JC, Reisfeld RA: A DNA vaccine targeting survivin combines apoptosis with suppression of angiogenesis in lung tumor eradication. Cancer Res 2005, 65:553-561

22. Otto K, Andersen MH, Eggert A, Keikavoussi P, Pedersen LO, Rath JC, Bock M, Brocker EB, Straten PT, Kampgen E, Becker JC: Lack of toxicity of therapy-induced $T$ cell responses against the universal tumour antigen survivin. Vaccine 2005, 23:884-889

23. Gyurkocza B, Plescia J, Raskett CM, Garlick DS, Lowry PA, Carter BZ, Andreeff M, Meli M, Colombo G, Altieri DC: Antileukemic activity of shepherdin and molecular diversity of hsp90 inhibitors. J Natl Cancer Inst 2006, 98:1068-1077

24. Meli M, Pennati M, Curto M, Daidone MG, Plescia J, Toba S, Altieri DC, Zaffaroni N, Colombo G: Small-molecule targeting of heat shock protein 90 chaperone function: rational identification of a new anticancer lead. J Med Chem 2006, 49:7721-7730

25. Li F: Role of survivin in cancer chemoprevention. Assay DesignsSimply Science 2005, 1:2-6

26. Azrak RG, Frank CL, Ling X, Slocum HK, Li F, Foster BA, Rustum YM The mechanism of methylselenocysteine and docetaxel synergistic activity in prostate cancer cells. Mol Cancer Ther 2006, 5:2540-2548

27. Christine Pratt MA, Niu M, White D: Differential regulation of protein expression, growth and apoptosis by natural and synthetic retinoids. J Cell Biochem 2003, 90:692-708

28. Pratt MA, Niu MY, Renart LI: Regulation of survivin by retinoic acid and its role in paclitaxel-mediated cytotoxicity in MCF-7 breast cancer cells. Apoptosis 2006, 11:589-605

29. Li F, Ling $X$, Huang $H$, Brattain L, Apontes $P, W u ~ J$, Binderup L, Brattain MG: Differential regulation of survivin expression and apoptosis by vitamin $\mathrm{D}(3)$ compounds in two isogenic MCF-7 breast cancer cell sublines. Oncogene 2005, 24:1385-1395

30. Xia F, Altieri DC: Mitosis-independent survivin gene expression in vivo and regulation by p53. Cancer Res 2006, 66:3392-3395

31. Li F, Altieri DC: Transcriptional analysis of human survivin gene expression, Biochem J 1999, 344 Pt 2:305-311

32. Li F, Ambrosini G, Chu EY, Plescia J, Tognin S, Marchisio PC, Altier DC: Control of apoptosis and mitotic spindle checkpoint by survivin. Nature 1998, 396:580-584

33. Li F, Altieri DC: The cancer antiapoptosis mouse survivin gene: characterization of locus and transcriptional requirements of basal and cell cycle-dependent expression. Cancer Res 1999, 59:3143-3151

34. Kaplan PJ, Mohan S, Cohen P, Foster BA, Greenberg NM: The insulin-like growth factor axis and prostate cancer: lessons from the transgenic adenocarcinoma of mouse prostate (TRAMP) model. Cancer Res 1999, 59:2203-2209

35. Serfas MS, Goufman E, Feuerman MH, Gartel AL, Tyner AL: p53independent induction of p21WAF1/CIP1 expression in pericentral hepatocytes following carbon tetrachloride intoxication. Cell Growth Differ 1997, 8:951-961

36. Wu J, Ling X, Pan D, Apontes P, Song L, Liang P, Altieri DC, Beerman $\mathrm{T}$, Li F: Molecular mechanism of inhibition of survivin transcription by the GC-rich sequence selective DNA-binding antitumor agent, hedamycin: evidence of survivin downregulation associated with drug sensitivity. J Biol Chem 2005, 280:9745-9751

37. Ling X, Bernacki RJ, Brattain MG, Li F: Induction of survivin expression by taxol (paclitaxel) is an early event which is independent on taxol-mediated G2/M arrest. J Biol Chem 2004, 279:15196-15203

38. Spaulding B, Pan D, Ghadersohi A, Nielsen G, Jensen S, Gellert F, Ling $X$, Zhang M, Black A, Li F: Characterization of the 12C4 survivin monoclonal antibody and insight into the expression of survivin in human adult tissues. Histopathology 2006, 49:622-633

39. Ghadersohi A, Pan D, Fayazi Z, Hicks DG, Winston JS, Li F: Prostatederived Ets transcription factor (PDEF) downregulates survivin expression and inhibits breast cancer cell growth in vitro and xenograft tumor formation in vivo. Breast Cancer Res Treat 2007, 102:19-30

40. Ghadersohi A, Odunsi K, Zhang S, Azrak RG, Bundy BN, Manjili MH, Li F: Prostate-derived Ets transcription factor as a favorable prognostic marker in ovarian cancer patients. Int J Cancer 2008, 123:1376-1384

41. Deguchi M, Shiraki K, Inoue H, Okano H, Ito T, Yamanaka T, Sugimoto K, Sakai T, Ohmori S, Murata K, Furusaka A, Hisatomi H, Nakano T: Expression of survivin during liver regeneration. Biochem Biophys Res Commun 2002, 297:59-64

42. You L, He B, Xu Z, Uematsu K, Mazieres J, Fujii N, Mikami I, Reguart N Mclntosh JK, Kashani-Sabet M, McCormick F, Jablons DM: An antiWnt-2 monoclonal antibody induces apoptosis in malignant melanoma cells and inhibits tumor growth. Cancer Res 2004, 64:5385-5389

43. You L, He B, Xu Z, Uematsu K, Mazieres J, Mikami I, Reguart N, Moody TW, Kitajewski J, McCormick F, Jablons DM: Inhibition of Wnt-2-mediated signaling induces programmed cell death in nonsmall-cell lung cancer cells. Oncogene 2004, 23:6170-6174

44. Zhang T, Otevrel T, Gao Z, Ehrlich SM, Fields JZ, Boman BM: Evidence that APC regulates survivin expression: a possible mechanism contributing to the stem cell origin of colon cancer. Cancer Res 2001, 61:8664-8667 
45. Kim PJ, Plescia J, Clevers H, Fearon ER, Altieri DC: Survivin and molecular pathogenesis of colorectal cancer. Lancet 2003, 362:205-209

46. Zhang T, Fields JZ, Ehrlich SM, Boman BM: The chemopreventive agent sulindac attenuates expression of the antiapoptotic protein survivin in colorectal carcinoma cells. J Pharmacol Exp Ther 2004, 308:434-437

47. Townes TM, Lingrel JB, Chen HY, Brinster RL, Palmiter RD: Erythroidspecific expression of human beta-globin genes in transgenic mice. EMBO J 1985, 4:1715-1723

48. Hammer RE, Krumlauf R, Camper SA, Brinster RL, Tilghman SM: Diversity of alpha-fetoprotein gene expression in mice is generated by a combination of separate enhancer elements. Science 1987 235:53-58

49. Wu J, Apontes P, Song L, Liang P, Yang L, Li F: Molecular mechanism of upregulation of survivin transcription by the AT-rich DNA-binding ligand. Hoechst33342: evidence for survivin involvement in drug resistance. Nucleic Acids Res 2007, 35:2390-2402

50. Mirza A, McGuirk M, Hockenberry TN, Wu Q, Ashar H, Black S, Wen SF, Wang L, Kirschmeier P, Bishop WR, Nielsen LL, Pickett CB, Liu S: Human survivin is negatively regulated by wild-type p53 and participates in p53-dependent apoptotic pathway. Oncogene 2002, 21:2613-2622

51. Hoffman WH, Biade S, Zilfou JT, Chen J, Murphy M: Transcriptional repression of the anti-apoptotic survivin gene by wild type p53. J Biol Chem 2002, 277:3247-3257

52. Zhu N, Gu L, Findley HW, Chen C, Dong JT, Yang L, Zhou M: KLF5 Interacts with p53 in regulating survivin expression in acute lymphoblastic leukemia. J Biol Chem 2006, 281:14711-14718

53. Sayeed A, Konduri SD, Liu W, Bansal S, Li F, Das GM: Estrogen receptor alpha inhibits p53-mediated transcriptional repression: implications for the regulation of apoptosis. Cancer Res 2007, 67:7746-7755

54. Vaira V, Lee CW, Goel HL, Bosari S, Languino LR, Altieri DC: Regulation of survivin expression by IGF-1/mTOR signaling. Oncogene 2007, 26:2678-2684

55. Zhao J, Tenev T, Martins LM, Downward J, Lemoine NR: The ubiquitin-proteasome pathway regulates survivin degradation in a cell cycle-dependent manner. J Cell Sci 2000, 113 Pt 23:4363-4371

56. Fukuda S, Pelus LM: Regulation of the inhibitor-of-apoptosis family member survivin in normal cord blood and bone marrow CD34(+) cells by hematopoietic growth factors: implication of survivin expression in normal hematopoiesis. Blood 2001, 98:2091-2100

57. Ciesielski MJ, Apfel L, Barone TA, Castro CA, Weiss TC, Fenstermaker RA: Antitumor effects of a xenogeneic survivin bone marrow derived dendritic cell vaccine against murine GL261 gliomas. Cancer Immunol Immunother 2006, 55:1491-1503

58. Okazaki T, Magaki T, Takeda M, Kajiwara Y, Hanaya R, Sugiyama K, Arita K, Nishimura M, Kato Y, Kurisu K: Intravenous administration of bone marrow stromal cells increases survivin and Bcl-2 protein expression and improves sensorimotor function following ischemia in rats. Neurosci Lett 2008, 430:109-114
59. Carlsson G, Boxhammer S, Garwicz D, Henter JI, Palmblad J, Nordenskjold M, Porwit A, Fadeel B: Survivin expression in the bone marrow of patients with severe congenital neutropenia. Leukemia 2008, 23:622-625

60. Ling X, Wu J, He X, Das G, Veith J, Bernacki RJ, Zhou M, Cao X, Li F: Estrogen upregulates survivin expression in breast cancer cells via both genomic and non-genomic mechanisms: Involvement of the MAPK signaling pathway and $\mathrm{ER} \alpha$-mediated promotion of $\mathrm{Sp} 1$ function (\#5192). AACR, San Diego, CA, 2008, p. 1237

61. Miyachi K, Sasaki K, Onodera S, Taguchi T, Nagamachi M, Kaneko H, Sunagawa M: Correlation between survivin mRNA expression and lymph node metastasis in gastric cancer. Gastric Cancer 2003, 6:217-224

62. Wobser M, Keikavoussi P, Kunzmann V, Weininger M, Andersen MH, Becker JC: Complete remission of liver metastasis of pancreatic cancer under vaccination with a HLA-A2 restricted peptide derived from the universal tumor antigen survivin. Cancer Immunol Immunother 2006, 55:1294-1298

63. Marioni G, Bertolin A, Giacomelli L, Marchese-Ragona R, Savastano M Calgaro N, Marino F, De Filippis C, Staffieri A: Expression of the apoptosis inhibitor protein Survivin in primary laryngeal carcinoma and cervical lymph node metastasis. Anticancer Res 2006, 26:3813-3817

64. Thomas J, Liu T, Cotter MA, Florell SR, Robinette K, Hanks AN Grossman D: Melanocyte expression of survivin promotes development and metastasis of UV-induced melanoma in HGF-transgenic mice. Cancer Res 2007, 67:5172-5178

65. Ouhtit A, Matrougui K, Bengrine A, Koochekpour S, Zerfaoui M Yousief Z: Survivin is not only a death encounter but also a survival protein for invading tumor cells. Front Biosci 2007, 12:1260-1270

66. Boman BM, Walters R, Fields JZ, Kovatich AJ, Zhang T, Isenberg GA, Goldstein SD, Palazzo JP: Colonic crypt changes during adenoma development in familial adenomatous polyposis: immunohistochemical evidence for expansion of the crypt base cell population. Am J Pathol 2004, 165:1489-1498

67. Woodward WA, Chen MS, Behbod F, Alfaro MP, Buchholz TA, Rosen $\mathrm{JM}$ : WNT/beta-catenin mediates radiation resistance of mouse mammary progenitor cells. Proc Natl Acad Sci USA 2007, 104:618-623

68. Glinsky GV: Genomic models of metastatic cancer: functional analysis of death-from-cancer signature genes reveals aneuploid, anoikisresistant, metastasis-enabling phenotype with altered cell cycle control and activated Polycomb Group (PcG) protein chromatin silencing pathway. Cell Cycle 2006, 5:1208-1216

69. Li F: Every single cell clones from cancer cell lines growing tumors in vivo may not invalidate the cancer stem cell concept. Mol Cells 2009, 27:491-492

70. Zipori D: The nature of stem cells: state rather than entity. Nat Rev Genet 2004, 5:873-878

71. Lander AD: The 'stem cell' concept: is it holding us back? J Biol 2009, $8: 70(71-76)$ 